\title{
How to Be a Qualified University Student Majoring in Civil Engineering
}

\author{
Ruijun Suo ${ }^{1, a}$ and Qinghui Suo ${ }^{2, b}, *$ \\ ${ }^{1}$ School of Urban Construction, Yangtze University, Jingzhou, Hubei, China \\ ${ }^{2}$ School of Engineering and Technology, Southwest University, Chongqing, China \\ aruijun_suo@163.com, bsuo@swu.edu.cn \\ *corresponding author
}

Keywords: Civil Engineer, University Students, Time Management, Review, Computer Software

\begin{abstract}
The university education is the basis for being a professional civil engineer and how to study effectively during the university education is important for the students. This paper suggests that students should focus on time management, knowledge review and computer software while studying.
\end{abstract}

\section{Introduction}

Civil engineering is a professional engineering discipline that deals with the design, construction and maintenance of the physical and natural built environment, including works like roads, bridges, canals, dams and buildings [1]. The main duties of civil engineering work include planning and overseeing construction work, analyzing construction sites and jobs, ensuring the fluency of procedure and safety of work environment. The role of a civil engineer is extremely important as it equates for the overall safety of society in many different facets. University education is the basis for a student to be a qualified civil engineer after graduation. For a qualified university student in civil engineering, studying effectively should be optimal, instead of studying hard only. This paper focus on how to study effectively while in the campus. Students should do well in following aspects while in the university.

\section{Managing time reasonably}

Normally the university offer bachelor degree of Civil Engineering which is usually completed in four years of full-time study; during the period, nearly 100 curriculum should be finished and the students should pass the course exam successfully to take enough credit to graduate. The importance of the curriculum is different, and they should not be treated equally. The amount of time spent in lectures varies greatly according to the importance of the curriculum.

The core curriculum of civil engineering introduces principles of structural analysis and design, construction procedure, budget estimate and so on. It provides grounding in the fundamentals of civil engineering, and incorporates project-based labs that teach the processes and skills involved in planning, design and construction; the curriculum provide students with both a rigorous foundation in theory and the practical, hands-on experience they need to succeed in the field. The students should spend more time on the core curriculum and less time on the others. The time should be managed reasonably and it could not divide equally in each course. Some core curriculum, such as the course of structural mechanic and reinforced concrete design, should pay more attention.

Which curriculum are core is another problem that should be payed attention to. The teachers can help the students to assess the importance of the curriculum according the students' career plan. For example, if the students want to engage in building engineering, the structural mechanics, building construction, high-rise building, and so on are the core curriculum. After identifying the core curriculum, their classes will feel more deliberate and relevant. Rather than taking a number of general classes, the topics will all be relevant to students' interests or area of major study. 


\section{Review the knowledge periodically}

Lectures will probably make up a large proportion of the learning in the university, keep concentrating in the classroom is important. Although taking note is not compulsive, it suggests that students had better take notes, and review the notes periodically. The retention of skill is poor when mass practicing is used [2], why retention is poorer when mass practice could be explained by the theories on deficient memory consolidation $[3]$.

For example, at the end of each week, go through your notes for all of your classes to ensure you understand the content. Rewrite any lecture notes if they are too messy or disorganized. Organize your notes into binders or file folders. Ensure the notes are placed in sequence with other notes. Make summary notes on the important concepts and information. Look at how the material covered relates to the course as a whole [4].

Do practice problem is another way to review the knowledge. Sometime the students feel familiar with the knowledge, but they make mistake while putting knowledge into practice. For being a qualified engineer in the future, doing as many practice problem as possible is encourage while study in the university.

\section{Learning computer software}

The usage of computer technology has covered different areas of civil engineering. For example, the software which is used to design buildings is known as "AutoCAD", which makes structural design process very easy and gives engineers the best options to design a perfect map for a building [5]. One of the most important software for managing a civil engineering construction project is "JustWin", which is operated with the help of computer. Major civil engineering related projects, programs and schedule tasks can be easily managed through this software. The most popular structural calculating and analysis software name 'PKPM', which is developed by Chinese Academy of Building Research, make structural analysis very quickly and easily [6]. Latest computer technology will play a vital role in civil engineering projects, and civil engineers will feel fewer burdens on their shoulders if they can use the computer-aided technique.

\section{Conclusions}

The university education is basis for being a professional civil engineer and how to study effectively during the university education is important for the students. It suggests that students should focus on time management, knowledge review and computer software while studying.

\section{References}

[1] Wikipedia, Civil Engineering, available at: https://en.wikipedia.org/wiki/Civil_engineering\#cite_note-1J.

[2] Craen, S.D., and Vlakveld, W.P. 2013. Young drivers who obtained their licence after an intensive driving course report more incidents than drivers with a traditional driver education. Accident Analysis and Prevention. 58, 64-69.

[3] McGaugh, J.L. 2000. Memory - a century of consolidation. Science, 287, 248-251.

[4] Learning commons. A Guide to University Learning. Available at:

http://www.learningcommons.uoguelph.ca/guides/university_learning/accessibility/studying.html.

[5] GamesHT. Usage of Computer Technology in Civil Engineering. Available at: https://www.gamesht.com/2012/11/09/usage-of-computer-technology-in-civil-engineering/

[6] Baidu. PKPM. Available at: https://baike.baidu.com/item/PKPM/3858718?fr=aladdin 